\title{
The Long-Term Impact of Excision of Benign Non-Endometriotic Ovarian Cysts on Ovarian Reserve and Reproductive Performance: A Cohort Study Long-Term Ovarian Reserve Status After Ovarian Cystectomy
} \author{
Azza Aboelfadle ${ }^{4}$, and Saad Amer*1 \\ ${ }^{1}$ Department of Obstetrics and Gynaecology, University of Nottingham, United Kingdom \\ ${ }^{2}$ University Hospitals of Derby and Burton NHS Foundation Trust, United Kingdom \\ ${ }^{3}$ Department of Obstetrics and Gynaecology Assuit University, Egypt \\ ${ }^{4}$ Department of Clinical Pathology, Assuit University, Egypt \\ ${ }^{5}$ West Middlesex University Hospital, London
}

Ahmed Mohamed ${ }^{1,3}$, Michael Jones ${ }^{2}$, Tarek El Shamy ${ }^{2,5}$, Tarek Al Hussaini ${ }^{3}$, John Monaghan², Tarek Farghaly ${ }^{3}$,

Submission: May 23, 2020; Published: June 08, 2020

*Corresponding author: Saad A K S Amer, Associate Professor in Gynaecology, School of Medicine University of Nottingham, Royal Derby Hospital Centre Uttoxeter Road, Derby DE22 3DT United Kingdom

\section{Abstract}

The purpose of this study was to assess long-term ovarian reserve status and reproductive performance after ovarian cystectomy. This cohort study included 38 women with history of excision of benign non-endometriotic ovarian cysts ( $>1$ year before the study) and 41 healthy controls. Study procedures included completion of a questionnaire, an interview, a transvaginal ultrasound scan, and a blood test for ovarian reserve biomarkers. The primary outcome was serum Anti-Müllerian Hormone (AMH) concentration as a marker of ovarian reserve. Both groups were similar in age (study, $34.1 \pm 6.8$ years; control, $35.3 \pm 6.7$ years) and BMI (study, $26.1 \pm 5.1$; control, $25.3 \pm 5.0 \mathrm{~kg} / \mathrm{m} 2$ ). The mean $\pm \mathrm{SD}$ ovarian cyst diameter was $6.6 \pm 1.9 \mathrm{~cm}$ and the median (IQR) duration of follow up was $6.0(4.0-7.3)$ years. There was no statistically significant $(\mathrm{P}>0.05)$ difference in serum AMH concentration between the study $(1.3(0.5-2.4) \mathrm{ng} / \mathrm{ml})$ and the control groups $(1.5(0.6-2.5) \mathrm{ng} / \mathrm{ml})$. Sub-analysis of women aged $<40$, also revealed no statistically significant difference in serum AMH levels between the two groups (Study ( $\mathrm{n}=28), 1.7(0.7-3.1)$ vs. controls $(\mathrm{n}=30), 1.7(0.7-3.2) \mathrm{ng} / \mathrm{ml})$. Other ovarian reserve markers were not statistically different between the two groups. Amongst women seeking fertility, pregnancy rates were significantly $(\mathrm{p}<0.001)$ lower in the study group $(20 / 31,64.5 \%)$ versus healthy controls $(28 / 28,100 \%)$. In conclusion, excision of benign non-endometriotic ovarian cyst does not seem to affect ovarian reserve in the long-term. However, it may compromise subsequent reproductive performance, but the study was underpowered for this outcome.

Keywords: Anti-Müllerian hormone; Ovarian cystectomy; Ovarian reserve; Reproductive performance; Ovarian function; Antral follicle count

\section{Introduction}

Ovarian cystectomy is a very common procedure in gynaecological practice. There has recently been a growing concern that this procedure is associated with a significant compromise to ovarian reserve. Previous research reported that cystectomy was associated with concomitant excision of normal ovarian tissue resulting in significant follicle loss [1,2]. Furthermore, several recent studies have consistently reported decline in ovarian reserve as measured by circulating Anti Müllerian Hormone (AMH) after excision of benign ovarian cysts [3-9]. Our recent meta-analysis has shown about 38\% decline in circulating $\mathrm{AMH}$ after excision of benign non-endometriotic ovarian cysts, which was sustained for up to six months [10]. The possible impact of 
this postoperative decline in ovarian reserve on long-term fertility potential remains to be investigated. Ovarian reserve refers to the functional reproductive potential of the ovary. It reflects the number and quality of the remaining primordial follicles at any given time. Currently, several tests are used to assess ovarian reserve including biochemical markers (FSH, LH and antiMüllerian hormone $(\mathrm{AMH})$ ) and sonographic markers (Antral Follicle Count (AFC), Ovarian Volume (OV). AMH is produced exclusively from the granulosa cells of primary and small antral follicles [11]. Serum AMH has been widely accepted as a reliable marker of ovarian reserve $[12,13]$. It offers several advantages over other markers such as its relative stability throughout the menstrual cycle with minimal or no fluctuation [14]. The purpose of the current study was to investigate the long-term effect of excision of benign non-endometriotic ovarian cyst on circulating $\mathrm{AMH}$ and ovarian reserve markers and on pregnancy rates.

\section{Materials and Methods}

The protocol of the study was approved by the National Research Ethics Committee of the East Midlands, UK [REC Reference: 16/EM/0244] and The Institutional Review Board at Faculty of Medicine, Assuit University, Egypt [IRB Ref: IRB17200052]. All study methods were conducted in accordance with the ethical principles that have their origin in the Declaration of Helsinki, 1996; the principles of Good Clinical Practice, and the Department of Health Research Governance Framework for Health and Social care, 2005.

\section{Participants}

\section{Study group}

This study was conducted in two collaborating hospitals including Royal Derby Hospital (UK) and Assuit Women Health Hospital (Egypt) between 2016 and 2017. Participants included women who had previously undergone ovarian cystectomy between January 2005 and December 2014 for benign nonendometriotic ovarian cysts (age at surgery $\leq 38$ years). Women were recruited if they were aged $\leq 48$ years at follow-up and were willing and able to give informed consent for participation in the study. Exclusion criteria included concurrent treatments, which could affect participants' hormonal status such as combined hormonal contraception, ovarian suppression therapy, fertility treatment or corticosteroid therapy; any condition, which may influence the serum AMH level or ovarian function such as polycystic ovarian syndrome, severe ovarian endometriosis, uncontrolled thyroid disease, suspected ovarian malignancy, premature menopause and current pregnancy. Potential participants were identified from the operative theatre database and from women attending gynaecological outpatient clinics at both sites of the study (Figure 1). Hospital records of identified women were screened for eligibility. Those who were suitable for study were invited to take part by either sending an invitation letter with the patient information sheet or directly handing these in the clinic.

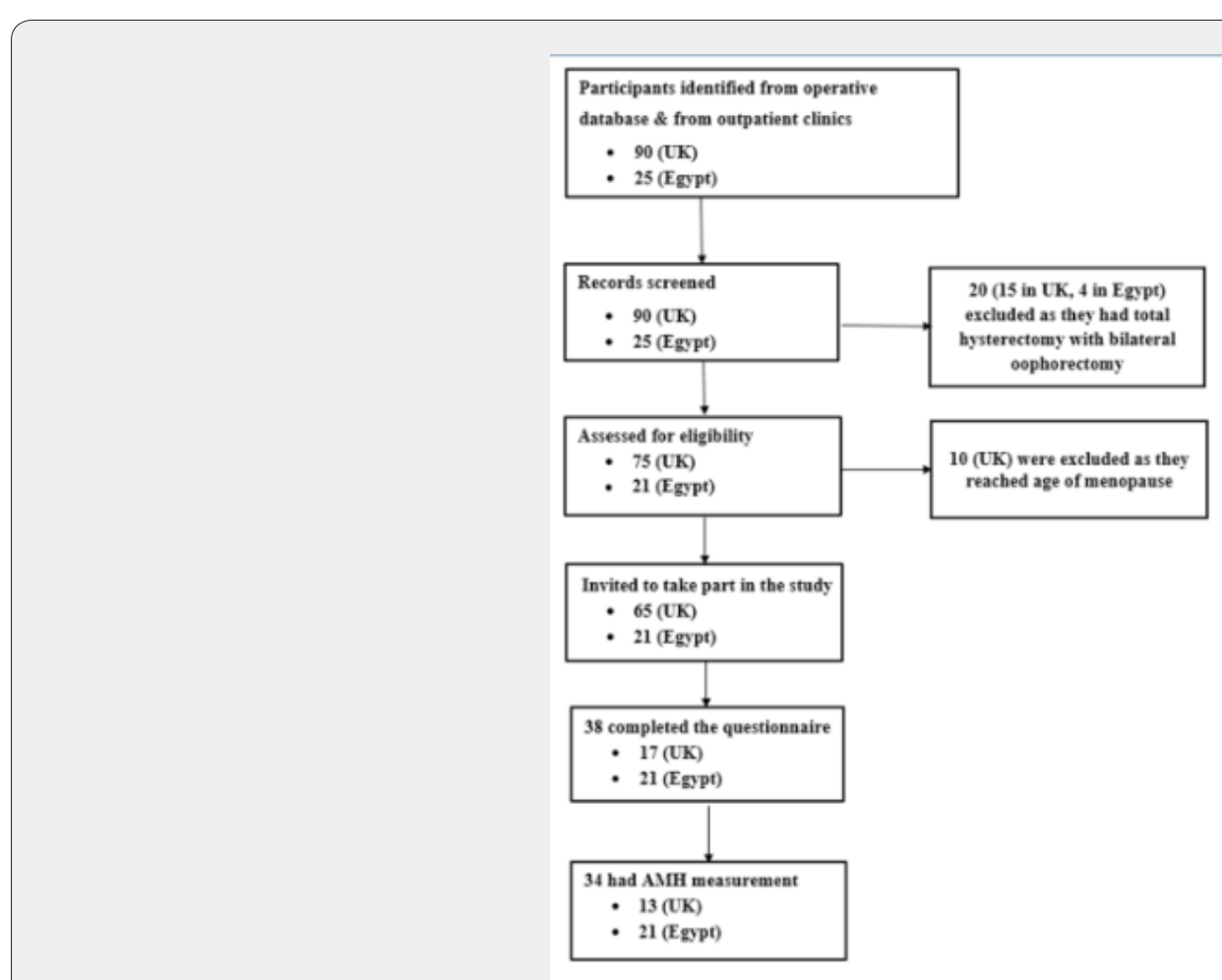

Figure 1: Flowchart of participants' identification and recruitment in both sites of the study. 


\section{Control group}

This group included healthy women with no known pelvic pathology and with no history of previous ovarian surgery or infertility. They were identified from women attending gynaecological outpatient clinics and from hospital staff and students. Suitable control participants of a previous similar study conducted by our group were also included in this group (Their anonymous data were retrieved from the study dataset).

Participants in the control group were matched by age and BMI (at recruitment) to women in the study group. Each control participant was matched with the same BMI and age category of a study participant. BMI categories included underweight $\left(\mathrm{BMI}<18.5 \mathrm{~kg} / \mathrm{m}^{2}\right)$, healthy weight $\left(\mathrm{BMI}, 18.5-24.9 \mathrm{~kg} / \mathrm{m}^{2}\right)$ and overweight (BMI $\geq 25.0 \mathrm{~kg} / \mathrm{m}^{2}$ ). Age categories included $>30$ years, 31- 40 years, $>40$ years.

\section{Study Procedures}

Invited women who agreed to participate in the study were asked to complete a questionnaire covering medical, surgical and reproductive history. They were also invited to attend the hospital for a short interview, a blood test and an ultrasound scan. All those attending the hospital visit gave a written informed consent. A transvaginal ultrasound scan of the ovaries was performed (on cycle day 2-4 if they are menstruating or at any time if amenorrheic) to assess the Antral Follicle Count (AFC) and ovarian volume (OV). All scans were performed by three experienced Gynaecologists. A systematic approach was used for counting antral follicles measuring $2-10 \mathrm{~mm}$ in mean diameter [15]. Ovarian volume was calculated using the prolate ellipsoid formula $(\mathrm{L} \times \mathrm{H} \times \mathrm{W} \times 0.523)$ [16]. The hospital records of study group participants were retrieved and reviewed for their medical, surgical and reproductive history. In addition, details of their ovarian cystectomy were recorded including route of surgery (open or laparoscopic), cyst size \& laterality, techniques used for cystectomy, hemostatic measures applied and whether the ovary was reconstructed by suturing.

\section{Laboratory assay}

Venous blood $(5 \mathrm{~mL})$ was withdrawn on cycle day 2-4 or at a random time in amenorrheic women. The samples were immediately transferred to the laboratory of each centre, centrifuged for 15 minutes at $2000 \mathrm{X}$ g at $4{ }^{\circ} \mathrm{C}$ and stored at -80 ${ }^{\circ} \mathrm{C}$ for later analysis for $\mathrm{AMH}$ and $\mathrm{FSH}$ concentrations. The same assays were used in the two centres. Serum FSH levels were measured using enzyme-linked fluorescent assays according to the manufacturers' instructions. The serum AMH levels were measured using the Roche e-601 automated analyzer (Roche Diagnostics). Reported limit of detection is $0.08 \mathrm{pmol} / \mathrm{L}$. Interassay performance at $37.2 \mathrm{pmol} / \mathrm{L}$ and $6.33 \mathrm{pmol} / \mathrm{L}$ has a $\%$ coefficient of variation (CV) of 2.8 and 3.1 respectively. Intra-assay performance at $23.4 \mathrm{pmol} / \mathrm{L}$ gave a $\% \mathrm{CV}$ of 0.57 .

\section{Sample size}

Power calculation for this study was based on the Ercan study, which reported a mean \pm SD AMH concentration of $2.06 \pm 0.51 \mathrm{ng} /$ $\mathrm{ml}$ for normo-ovulatory women [17]. A sample size of 34 in each group was estimated to detect a minimum clinically important difference in circulating $\mathrm{AMH}$ of $0.5 \mathrm{ng} / \mathrm{ml}$ with $86 \%$ power and a 0.05 two-sided significance level using a Wilcoxon (MannWhitney) rank-sum test.

\section{Statistical analyses}

Numerical data were compered between the two groups using unpaired t-test or Mann-Whitney U test with a 0.050 two-sided significance level as appropriate. Categorical data were compared using chi-squared test, with a 0.050 two-sided significance level.

\section{Results}

The study included 38 women with a history of ovarian cystectomy for non-endometriotic ovarian cysts and 41 healthy controls. Figure 1 shows a flowchart of identification and selection of participants of the study group in both centres. Thirty-four women attended the hospital for assessment of ovarian reserve including serum levels of AMH and FSH, OV and AFC (Figure 1). Table 1 shows the characteristics of study and control participants. Both groups were comparable for age, BMI, menstrual pattern and smoking status. The median (IQR) duration of follow up after surgery was 6.0 (4.0-7.3) years. Regarding hormonal contraception, three study participants (7.9\%) reported using progestogen only contraception versus 11 (26.8\%) control participants $(\mathrm{p}=0.016)$. The remaining participants either used non-hormonal contraceptive methods (study, $\mathrm{n}=1$ [2.6\%]; control, $\mathrm{n}=3[7.3 \%]$ ) or did not use any contraception (study, $\mathrm{n}=34$ [89.5\%]; control, $\mathrm{n}=27$ [65.9\%]).

\section{Surgical procedures}

The surgical details of ovarian cystectomy are summarized in table 2. All operations were performed by senior experienced Gynaecological surgeons. In about two thirds of the patients $(68.4 \%)$ the procedure was carried out through laparotomy and one third was performed laparoscopically (Table 2). In most cases, surgery started with an incision in the cyst capsule taking care not to open the cyst. With careful sharp, blunt and hydro- dissection the cyst was then removed from the ovarian capsule. If the cyst accidently opened, its contents were thoroughly washed of the pelvis and abdomen. Any bleeding points in the ovarian cyst bed were diathermised with bipolar electro-coagulation avoiding excessive ovarian damage. Suturing of the ovary was used in most cases. 
Table 1: The demography of the study and control participants.

\begin{tabular}{|c|c|c|c|}
\hline Characteristics & $\begin{array}{c}\text { Cystectomy Group } \\
(n=38)\end{array}$ & Control Group $(n=41)$ & $\mathbf{P}$ \\
\hline Age (years) & $34.1 \pm 6.8$ & $35.3 \pm 6.7$ & 0.429 \\
\hline BMI $\left(\mathrm{kg} / \mathrm{m}^{2}\right)$ & $26.1 \pm 5.1$ & $25.3 \pm 5.0$ & 0.469 \\
\hline Smoking & $2(5.3 \%)$ & $4(9.8 \%)$ & 0.375 \\
\hline Current contraception & $4(10.5 \%)$ & $14(34.1 \%)$ & 0.016 \\
\hline - None & $34(89.5 \%)$ & $27(65.9 \%$ & \\
\hline$\cdot$ POPs & 2 & 1 & \\
\hline · Mirena & 1 & 6 & \\
\hline - Implant & 0 & 3 & \\
\hline - Injection-DMPA & 0 & 1 & \\
\hline - Barrier & 1 & 1 & \\
\hline · Copper IUD & 0 & 1 & \\
\hline -Sterilization & 0 & 1 & \\
\hline \multicolumn{4}{|c|}{ Menstrual pattern } \\
\hline - Regular & $29(76.3 \%)$ & $25(61.0 \%)$ & 0.271 \\
\hline - Infrequent ( $>5$ weeks) & $7(18.4 \%)$ & $10(24.4 \%)$ & \\
\hline - Frequent (<3 weeks) & $0(0.0 \%)$ & $3(7.3 \%)$ & \\
\hline - Absent* & $2(5.3 \%)$ & $3(7.3 \%)$ & \\
\hline
\end{tabular}

\section{Features of the ovarian cysts}

The mean \pm SD cyst diameter was $6.6 \pm 1.9 \mathrm{~cm}$. Most cysts were unilateral $(n=35,92.1 \%)$ and only three were bilateral (7.9\%). All cases had documented histopathology report determining type of excised cyst (Table 2). Simple (functional) cysts were the most common $(n=18,47.4 \%)$ followed by dermoid cysts $(n=12,31.6 \%)$, then cystadenoma $(n=7,18.4 \%)$. Luteoma of pregnancy was only reported in one case $(2.6 \%)$ which was discovered accidentally during caesarean section delivery. During follow up only one case showed recurrent cyst on the same side of surgery which was managed surgically by laparoscopic cystectomy $(2.6 \%)$. Indications for surgery are summarized in table 2 . Pain was the most common indication $(n=16,42.1 \%)$, followed by the cyst size being large $(n=10,26.3 \%)$ (Table 2$)$.

Table 2: Details of ovarian cystectomy and follow-up in study participants.

\begin{tabular}{|c|c|}
\hline Characteristics & Cystectomy Group $(n=38)$ \\
\hline Duration of follow up (years) & $6.0[4.0-7.3]$ \\
\hline Cyst diameter $(\mathrm{cm})$ & $6.6 \pm 1.9$ \\
\hline \multicolumn{2}{|c|}{ Laterality } \\
\hline Unilateral & $35(92.1 \%)$ \\
\hline Bilateral & $3(7.9 \%)$ \\
\hline \multicolumn{2}{|c|}{ Surgical approach } \\
\hline Laparoscopy & $12(31.6 \%)$ \\
\hline Laparotomy & $26(68.4 \%)$ \\
\hline \multicolumn{2}{|c|}{ Pathology } \\
\hline Dermoid, 12 (31.6\%) & $12(31.6 \%)$ \\
\hline Serous cystadenoma & $4(10.5 \%)$ \\
\hline Mucinous cystadenoma & $3(7.9 \%)$ \\
\hline Functional cyst & $18(47.4 \%)$ \\
\hline
\end{tabular}


Journal of Gynecology and Women's Health

\begin{tabular}{|c|c|}
\hline Luteoma of pregnancy & $1(2.6 \%)$ \\
\hline Pain & $16(42.1 \%)$ \\
\hline Large size & $10(26.3 \%)$ \\
\hline Infertility* & $4(10.5 \%)$ \\
\hline Pressure symptoms & $2(5.3 \%)$ \\
\hline Opportunistic* & $1(2.6 \%)$ \\
\hline
\end{tabular}

Data presented as mean $\pm \mathrm{sd}, \mathrm{n}(\%)$ and median [Interquartile]

${ }^{*}$ Cysts were found during fertility investigations

**a cyst removed during Caesarean section

\section{Serum AMH concentrations}

The median (IQR) serum AMH concentration of the study group was $1.3(0.5-2.4) \mathrm{ng} / \mathrm{ml}$, which was not significantly $(p=0.524)$ different from that $1.5(0.6-2.5) \mathrm{ng} / \mathrm{ml}$ of the healthy controls (Table 3). Sub analysis of women aged $<40$, also revealed no significant $(\mathrm{p}=0.932)$ difference in serum AMH levels between the two groups (Study $(\mathrm{n}=28), 1.7(0.7-3.1)$ vs. controls $(\mathrm{n}=30)$, 1.7 (0.7-3.2) ng/ml) (Table 3).

Table 3: Serum AMH concentrations and other ovarian reserve parameters after a median (IQR) duration of $6(4.0-7.3)$ years following ovarian cystectomy compared with healthy controls All data are presented as median [IQR], Mann-Whitney test used for comparison AMH, Anti-müllerian hormone; FSH, follicle stimulating hormone; AFC, antral follicle count; OV, ovarian volume.

\begin{tabular}{|c|c|c|c|}
\hline & Cystectomy Group & Control Group & P \\
\hline Overall & (n=34) & (n=41) & 0.595 \\
\hline AMH (ng/ml) & $1.3[0.5-2.4]$ & $6.6[5.4-8.7]$ & 0.492 \\
\hline FSH (IU/L) & $7.2[6.3-9.1]$ & $8.5[5.0-10.8]$ & 0.22 \\
\hline AFC (number) & $7.0[5.0-8.0]$ & $6.5[4.9-8.9]$ & 0.698 \\
\hline Average OV (cm3) & $7.5[4.0-10.4]$ & $(\mathrm{n}=30)$ & 0.932 \\
\hline Sub analysis age $<40$ (years) & $(\mathrm{n}=28)$ & $1.7[0.7-3.2]$ & 0.226 \\
\hline AMH (ng/ml) & $7.7[0.7-3.1]$ & $5.9[5.3-7.8]$ & $10.5[6.5-11.0]$ \\
\hline FSH (IU/L) & $7.0[5.9-8.4]$ & $7.4[5.6-9.9]$ & 0.133 \\
\hline AFC (number) & $8.7[4.9-12.3]$ & & 0.633 \\
\hline Average OV $\left(\mathrm{cm}^{3}\right)$ & & & \\
\hline
\end{tabular}

\section{Other ovarian reserve markers}

There was no statistically significant difference in the median (IQR) of other ovarian reserve markers as summarized in table 3.

\section{Reproductive performance}

Table 4 summarizes pregnancy rates amongst women seeking fertility in the study $(n=31)$ and control $(n=28)$ groups. The pregnancy rate in the study group after cystectomy $(20 / 31$, $64.5 \%)$ was significantly $(\mathrm{p}<0.001)$ lower than that of the controls $(28 / 28,100 \%)$ (Table 4$)$. The study group achieved a significantly $(\mathrm{p}<0.001)$ lower natural pregnancy (i.e. without fertility treatment) rate $(25.8 \%, 8 / 31)$, compared to a $100 \%$ rate achieved by the healthy controls. The remaining 12 pregnancies amongst the study group were achieved with fertility treatments as detailed in table 4 . Amongst the 31 women who tried to conceive after the cystectomy, 23 (74.2\%) experienced subfertility due to unknown cause $(14 / 23,60.8 \%)$, anovulation $(7 / 23,30.4 \%)$ or tubal factor $(2 / 23,8.7 \%)$. Table 4 also presents comparison of the pregnancy rates amongst women seeking fertility in the study group before $(\mathrm{n}=21)$ and after cystectomy $(\mathrm{n}=31)$. The natural pregnancy rates were significantly $(p<0.004)$ lower after surgery $(8 / 31,25.8 \%)$ compared to the rates $(14 / 21,66.7 \%)$ before surgery (Table 4$)$.

\section{Discussion}

To the best of our knowledge, this is the first study on the long-term impact of ovarian cystectomy on ovarian reserve and reproductive performance. We have assessed ovarian reserve markers in 34 women after a median (IQR) duration of 6 (4.0-7.3) years following excision of benign non-endometriotic ovarian cysts and compared the results with 41 healthy women of similar age and BMI. We found no statistically significant difference in circulating AMH and all other ovarian reserve markers between both groups. Subgroup analysis of participants aged $<40$ years still showed no difference in AMH between the two groups. On the other hand, pregnancy rates amongst women seeking fertility in the study group were significantly lower after surgery compared to their pregnancy rates before surgery and to the pregnancy rates of the controls. The findings of this study are surprising when considering the results of our recent systematic review, which 
showed significant postoperative decline in ovarian reserve [10]. The review, which included 10 studies $(n=367)$, showed a marked fall in circulating AMH of $1.14 \mathrm{ng} / \mathrm{mL}$ (weighted mean difference, $-1.14 \mathrm{ng} / \mathrm{ml}$; 95\% CI, -1.36 to -0.92), which was sustained for up to six months after surgery [10]. The short-term post-cystectomy fall in circulating $\mathrm{AMH}$ is thought to be due to concomitant removal of normal ovarian tissue with significant follicular loss $[1,18,19]$. Another possible mechanism is the thermal damage to ovarian tissue $[20,21]$ or vasculature due to excessive use of electrosurgical coagulation for hemostasis [22]. Our results are consistent with previous studies reporting partial recovery of circulating $\mathrm{AMH}$ within 12 months follow-up after ovarian cystectomy [3,8,22]. Chang et al reported that the initial post-cystectomy decline of circulating AMH tends to gradually recover at three-month followup to $\sim 65 \%$ of the preoperative level [3]. Ding et al reported that serum AMH levels recovered at six-months follow-up to almost $90 \%$ of the preoperative levels and to nearly $100 \%$ one year after surgery [8]. Similarly, Sugita et al found serum AMH to recover at one-year follow-up after excision of ovarian endometriomas [22]. The exact mechanism of the postulated recovery of circulating $\mathrm{AMH}$ after the initial post-cystectomy decline is uncertain. A possible explanation of this recovery could be the regeneration of new follicles [23-28]. Emergence of new follicles could either be derived from rescued atretic follicles $[23,24]$ or from the smaller follicle pool, termed reserve follicles [25]. Alternatively, surgeryinduced inflammation may stimulate the regeneration of ovarian follicles from either the ovarian surface epithelium [26,27] or from bone marrow stem cells [28]. The decline in the long-term reproductive performance after ovarian cystectomy is surprising given the normality of ovarian reserve. Mechanical subfertility due to postoperative peri-adnexal adhesions is a possible explanation. However, our data do not support this hypothesis, as tubal factor was responsible for infertility in only $8.7 \%$ of cases.

Table 4: Pregnancy rates amongst women seeking fertility in both groups.

\begin{tabular}{|c|c|c|c|}
\hline \multicolumn{4}{|c|}{ Study versus control groups } \\
\hline & $\begin{array}{l}\text { Study group after surgery } \\
\qquad(\mathrm{n}=31) \mathrm{n}(\%)\end{array}$ & $\begin{array}{l}\text { Control group }(\mathrm{n}=28) \\
\mathrm{n}(\%)\end{array}$ & $P$ \\
\hline Conception (overall) & $20(64.5)$ & $28(100.0)$ & $<0.001$ \\
\hline Natural conception: & $8(25.8)$ & $28(100 \%)$ & $<0.001$ \\
\hline Conception with treatment & $12(74.2)$ & - & \\
\hline $\mathrm{CC}$ & $6(30.0)$ & - & \\
\hline SIUI & $1(5.0)$ & - & \\
\hline IVF & $5(25.0)$ & - & \\
\hline \multicolumn{4}{|l|}{ Number of pregnancies: } \\
\hline 5 & $1(3.2)$ & $0(0.0)$ & \\
\hline 4 & $0(0.0)$ & $4(14.3 \%)$ & \\
\hline 3 & $1(3.2)$ & $10(35.7)$ & \\
\hline 2 & $2(6.5)$ & $12(42.9)$ & \\
\hline 1 & $16(51.6)$ & $2(7.1)$ & \\
\hline \multicolumn{4}{|c|}{ Study group: before versus after surgery } \\
\hline & Before surgery $(n=21)-n(\%)$ & After surgery $(n=31)-n(\%)$ & $\mathrm{P}$ \\
\hline Conception (overall) & $16(76.2)$ & $20(64.5)$ & 0.28 \\
\hline Natural conception: & $14(66.7)$ & $8(25.8)$ & 0.004 \\
\hline
\end{tabular}

Abbreviations: CC, Clomiphene Citrate; SIUI, stimulated intra-uterine insemination ( $n=1)$, IVF, in-vitro fertilization.

The main limitation of this study is the possible variations in the surgical techniques as several surgeons in the two centres carried out the cystectomy over a long period of time. However, all surgeons performing the cystectomies were experienced gynaecological surgeons and the procedures of ovarian cystectomy were standard in most cases in both centres. Another possible weakness could be the high rate of laparotomy in our cohort, which may have compromised fertility due to postoperative adhesion formation. However, as the cystectomy techniques are similar in the open and the laparoscopic approaches, the impact on ovarian reserve is likely to be similar. Unfortunately, subgroup analysis for open versus laparoscopy was not possible due to the relatively small numbers in each sub-group. Another potential limitation could be the differences in the use of Progestogen Only Contraception (POC) 
between the study and control groups. However, recent literature data suggest that the use of POC does not affect the serum levels of AMH [29]. Furthermore, these differences are unavoidable in population studies. It may be argued that the study design should have been a longitudinal cohort where the long-term ovarian reserve markers are compared with preoperative baseline values rather than with a control group. Whilst this argument is valid for short-term studies, the situation is different for long-term investigations due to the confounding effect of advancing age on ovarian reserve markers. It would be difficult to adjust for the age-related changes in AMH as these are widely varied in different women. Furthermore, the longitudinal cohort design may not be practically feasible in view of the long time between the two measurements. Moreover, given the well-known issues with $\mathrm{AMH}$ kits which have changed several times over the last decade, it is likely that different AMH kits would have been used at the two points, thus invalidating the comparison. Finally, our design has been widely used in many previous similar long-term studies on AMH [30-35]. It may also be argued that premature menopause should not have been an exclusion criterion in the study group as it may represent worst ovarian reserve damage after ovarian cystectomy. Although this may be true to some extent, we felt that premature menopause is unlikely to occur after cystectomy and that such a condition if identified could be coincidental. It is worth noting that we did not find any case of premature menopause amongst all screened post-cystectomy women.

Our results on reproduction should be interpreted with caution, as the study was not powered to address this outcome. Furthermore, the control group may not be an ideal group to compare pregnancy rates, as they are a selected fertile group of healthy women. We excluded women with history of subfertility, as these may not be representative of the normal healthy population. They may also have reproductive pathology that could influence their AMH levels. The reproductive outcome will therefore require further investigation with large studies sufficiently powered and appropriately designed to assess long-term reproductive performance after ovarian cystectomy. Whilst the long-term data on ovarian reserve after ovarian cystectomy are reassuring, patients with benign ovarian cysts should be counselled about the possible long-term decline in their fertility potential following surgery. Expectant and conservative approaches to benign ovarian cysts should therefore be considered whenever possible especially in young women desiring fertility. In conclusion, excision of benign non-endometriotic ovarian cysts does not seem to cause any longterm decline in ovarian reserve. However, the possible long-term decline in the reproductive performance remains a concern, which warrants further research.

\section{Acknowledgement}

We are grateful to all participants of the study and to staff in the Gynaecology outpatient departments in both sites of the study. We are also grateful to the Egyptian Cultural Centre \& Education bureau in London and the British Council in Cairo funding the Research Fellow to undertake the work.

Funding

This study was supported by the Egyptian Cultural Centre and Education Bureau in London and the British Council in Cairo, Egypt.

\section{References}

1. Muzii L, Bianchi A, Crocè C, Manci N, PB Panici PB (2002) Laparoscopic excision of ovarian cysts: is the stripping technique a tissue-sparing procedure? Fertil Steril 77(3): 609-614.

2. Vercellini P, Chapron C, De Giorgi O, Consonni D, Frontino G, et al. (2003) Coagulation or excision of ovarian endometriomas? Am J Obstet Gynecol 188(3): 606-610.

3. Chang HJ, Han SH, Lee JR, Jee BC, Lee BI, et al. (2010) Impact of laparoscopic cystectomy on ovarian reserve: serial changes of serum anti-Müllerian hormone levels. Fertil Steril 94(1): 343-349.

4. Mohamed ML, Nouh AA, El-Behery MM, Mansour SA (2011) Effect on ovarian reserve of laparoscopic bipolar electrocoagulation versus laparotomic hemostatic sutures during unilateral ovarian cystectomy. Int J Gynecol Obstet 114(1): 69-72.

5. Kim SH, Kwon SK, Kim DY, Chae HD, Kim CH, et al. (2013) The impact of laparoscopic ovarian cystectomy on serum anti-müllerian hormone levels in women with endometrioma and other benign ovarian cysts: a prospective cohort study. Fertil Steril 100(3): S363.

6. Kwon SK, Kim SH, Yun SC, Kim DY, Chae HD, et al. (2014) Decline of serum antimüllerian hormone levels after laparoscopic ovarian cystectomy in endometrioma and other benign cysts: a prospective cohort study. Fertil Steril 101(2):435-441.

7. Yoon BS, Kim YS, Seong SJ, Song T, Kim ML, et al. (2014) Impact on ovarian reserve after laparoscopic ovarian cystectomy with reduced port number: a randomized controlled trial. Eur J Obstet Gynecol Reproduct Biol 176: 34-38.

8. Ding Y, Yuan Y, Ding J, Chen Y, Zhang X, et al. (2015) Comprehensive assessment of the impact of laparoscopic ovarian cystectomy on ovarian reserve. J Mini Invasive Gynecol 22(7): 1252-1259.

9. Ergun B, Ozsurmeli M, Dundar O, Comba C, Kuru O, et al. (2015) Changes in markers of ovarian reserve after laparoscopic ovarian cystectomy. J Mini Invasive Gynecol 22(6): 997-1003.

10. Mohamed AA, Al-Hussaini TK, Fathalla MM, El Shamy TT, Abdelaal II, et al. (2016) The impact of excision of benign nonendometriotic ovarian cysts on ovarian reserve: a systematic review. Am J Obstet Gynecol 215(2): 169-176.

11. Hachisuga T, Kawarabayashi T (2002) Histopathological analysis of laparoscopically treated ovarian endometriotic cysts with special reference to loss of follicles. Hum Reprod 17(2): 432-435.

12. Van Rooij IA, Broekmans FJ, Te Velde ER, Fauser B, Bancsi L, et al. (2002) Serum anti-Müllerian hormone levels: a novel measure of ovarian reserve. Hum Reprod17(12): 3065-3071.

13. Fanchin R, Schonäuer LM, Righini C, Guibourdenche J, Frydman R, et al. (2003) Serum anti-Müllerian hormone is more strongly related to ovarian follicular status than serum inhibin B, estradiol, FSH and LH on day 3. Hum Reprod 18(2): 323-327.

14. Lambert-Messerlian G, Plante B, Eklund EE, Raker C, Moore RG (2016) Levels of antimüllerian hormone in serum during the normal menstrual cycle. Fertil Steril 105(1): 208-213. 
15. Broekmans FJ, de Ziegler D, Howles CM, Gougeon A, Trew G, et al. (2010) The antral follicle count: practical recommendations for better standardization. Fertil Steril 94(3): 1044-1051.

16. Pavlik EJ, DePriest PD, Gallion HH, Ueland F, Reedy M, et al. (2000) Ovarian volume related to age. Gynecol Oncol 77(3): 410-412.

17. Ercan CM, Sakinci M, Duru NK, Alanbay I, Karasahin KE, et al. (2010) Antimullerian hormone levels after laparoscopic endometrioma stripping surgery. Gynecol Endocrinol 26(6): 468-472.

18. Maneschi F, Marasá L, Incandela S, Mazzarese M, Zupi E (1993) Ovarian cortex surrounding benign neoplasms: a histologic study. Am J Obstet Gynecol 169 (2 Pt 1): 388-393.

19. Somigliana E, Ragni G, Benedetti F, Borroni R, Vegetti W, et al. (2003) Does laparoscopic excision of endometriotic ovarian cysts significantly affect ovarian reserve? Insights from IVF cycles. Hum Reprod 18(11): 2450-2453.

20. Kang JH, Kim YS, Lee SH, Kim WY (2015) Comparison of hemostatic sealants on ovarian reserve during laparoscopic ovarian cystectomy. Eur J Obstet Gynecol Reprod Biol 194: 64-67.

21. Pergialiotis V, Prodromidou A, Frountzas M, Bitos K, Perrea D, et al. (2015) The effect of bipolar electrocoagulation during ovarian cystectomy on ovarian reserve: a systematic review. Am J Obste Gynecol 213(5): 620-628.

22. Sugita A, Iwase A, Goto M, Nakahara T, Nakamura T, et al. (2013) One-year follow-up of serum antimüllerian hormone levels in patients with cystectomy: are different sequential changes due to different mechanisms causing damage to the ovarian reserve? Fertil Steril100(2): 516-522.

23. Peters H, Byskov AG, Himelstein-braw R, Faber M (1975) Follicular growth: the basic event in the mouse and human ovary. J Reprod Fetil 45(3): 559-566

24. Fujimori K, Nakamura RM, Tonetta SA, Di Zerega GS (1987) Cessation of transition-phase follicle growth in the guinea pig by follicle-regulatory protein. Biol Reprod 37(4): 812-822.

25. Greenwald GS (1973) Effect of an anti-PMS serum on ovulation and estrogen secretion in the PMS-treated hamster. Biology of Reproduction 9(4): 437-446.
26. Bukovsky A, Caudle MR, Svetlikova M, Upadhyaya B (2004) Origin of germ cells and formation of new primary follicles in adult human ovaries. Reprod Biol Endocrinol 2(1): 20.

27. Bukovsky A, Svetlikova M, Caudle MR (2005) Oogenesis in cultures derived from adult human ovaries. Reprod Biol Endocrinol 3(1):17.

28. Johnson J, Bagley J, Skaznik-Wikiel M, Lee HJ, Adams GB, et al. (2005) Oocyte generation in adult mammalian ovaries by putative germ cells in bone marrow and peripheral blood. Cell 122(2): 303-315.

29. Li HW, Wong CY, Yeung WS, Ho PC, Ng EH, et al. (2011) Serum antimüllerian hormone level is not altered in women using hormonal contraceptives. Contraception 83(6): 582-585.

30. Bentzen JG, Forman JL, Pinborg A, Pinborg A, Lidegaard Ø, et al. (2012) Ovarian reserve parameters: A comparison between users and nonusers of hormonal contraception. Reprod Biomed Online 25(6): 612619.

31. Petersen KB, Hvidman HW, Forman JL, Pinborg A, Larsen EC, et al. (2015) Ovarian reserve assessment in users of oral contraception seeking fertility advice on their reproductive lifespan. Hum Reprod 30(10): 2364-2375.

32. Deb S, Campbell BK, Pincott-Allen C, Clewes JS, Cumberpatch G et.al. (2012) Quantifying effect of combined oral contraceptive pill on functional ovarian reserve as measured by serum anti-Müllerian hormone and small antral follicle count using three-dimensional ultrasound. Ultrasound Obstet Gynecol 39(5): 574-580.

33. Kucera R, Ulcova-Gallova Z, Topolcan O. (2016) Effect of long-term using of hormonal contraception on anti-Müllerian hormone secretion. Gynecol Endocrinol. 32(5): 383-385.

34. van den Berg MH, Overbeek A, Lambalk CB, Kaspers GJL, Bresters D, et al. (2018) Long-term effects of childhood cancer treatment on hormonal and ultrasound markers of ovarian reserve. Hum Reprod 33(8): 1474-1488.

35. Turkcuoglu I, Melekoglu R (2018) The long-term effects of endometrioma surgery on ovarian reserve: a prospective case-control study. Gynecol Endocrinol 34(7): 612-615.

Your next submission with Juniper Publishers
will reach you the below assets
- Quality Editorial service
- Swift Peer Review
- Reprints availability
- E-prints Service
- Manuscript Podcast for convenient understanding
- Global attainment for your research
- Manuscript accessibility in different formats
( Pdf, E-pub, Full Tsext, Audio)
- Unceasing customer service
Track the below URL for one-step submission
https://juniperpublishers.com/online-submission.php

